\title{
PROJECTS FOR THE CONSTRUCTION OF RAILWAYS BETWEEN THE VOLGA AND THE DON IN 1930-1950s
}

\author{
Andrey V. Lunochkin \\ Volgograd State University, Volgograd, Russian Federation
}

\begin{abstract}
The article is devoted to the connection of the Volga and Don rivers with railways in the place of greatest convergence (Perevoloka) in the 1830-1850s. During this period Perevoloka has become a transport corridor of national significance, through which the main stream of the industrial and forest products was transferred from Central Russia and the Urals to the South of the country - the sea of Azov and the North Caucasus. The article discusses the project of A. Bestuzhev 1834, who bore the form of the most General propositions about the need to build such road. Due to the lack of specifics, the project was not approved by the officials of the Main Department of Railways and public buildings. The next project was a note by an unknown author, dating from about 1837. It contained detailed calculations of the amounts needed for the construction of two ways - on a railway-horse road and steam-powered road, as well as justification of the railway route between Dubovka suburb on the Volga river and the Kachalinskaya-on-Don village. This railway-horse road was built by the same name joint stock company in 1846, however, could not compete with horse-drawn transport. After the Crimean war, the proposal on connecting the Volga and Don railway was made by Baron A. Meyendorff, captain of Kassel company, engineer Joffry, mechanical engineer Davison, the Italian Consul in Taganrog de Rossi, but their proposals did not satisfy the government. Permission to conduct the survey was received in 1856 by Alexander Derevitsky and count N.I. Musin-Pushkin, but soon lost the rights to the project of company of N. Novosel, V. A. Kokorev and P.P. Melnikov. This joint stock company built the first Volga-Don railway in the South of Russia.
\end{abstract}

Key words: Lower Volga, Don, railways, Russia, 1930-1950s, Tsaritsyn, Dubovka, joint stock companies.

Citation. Lunochkin A.V. Projects for the construction of railways between the Volga and the Don in 19301950s. Vestnik Volgogradskogo gosudarstvennogo universiteta. Serija 4, Istorija. Regionovedenie. Mezhdunarodnye otnoshenija [Science Journal of Volgograd State University. History. Area Studies. International Relations], 2017, vol. 22, no. 2, pp. 69-75. (in Russian).

УДК 94(470+571)“1830/1850”

Дата поступления статьи: 29.09.2016

ББК 63.3(2)521-2

Дата принятия статьи: 25.12.2016

\section{ПРОЕКТЫ СТРОИТЕЛЬСТВА ЖЕЛЕЗНЫХ ДОРОГ МЕЖДУ ВОЛГОЙ И ДОНОМ В 30-50-Х ГОДАХ ХІХ ВЕКА}

\section{Андрей Валентинович Луночкин}

Волгоградский государственный университет, г. Волгоград, Российская Федерация

\footnotetext{
Аннотация. Статья посвящена проблеме соединения Волги и Дона железными дорогами в 1830-1850-х годах. В статье рассматриваются проект А. Бестужева 1834 г.; записка неизвестного автора, датируемая приблизительно 1837 г., и построенная в 1846 г. Дубовско-Качалинская конно-железная дорога; предложения сере홍 дины 1850-х гг. барона А. Мейендорфа; компании ротмистра Касселя, инженера Жоффрио и инженераㄱ. механика Дависона; прошение итальянского консула в Таганроге де-Росси; проект 1856 г. А.А. Деревицкого и графа Н.И. Мусина-Пушкина, вскоре уступивших права компании Н.А. Новосельского, В.А. Кокорева и П.П. Мельникова. Это акционерное общество и стало строителем первой на Юге России Волго-Донской железной дороги.

Ключевые слова: Нижняя Волга, Дон, железные дороги, Россия, 30-50-е гг. ХІХ в., Царицын, Дубовка, акционерные общества.
} 
Цитирование. Луночкин, А. В. Проекты строительства железных дорог между Волгой и Доном в 30-50-х годах XIX века / А. В. Луночкин // Вестник Волгоградского государственного университета. Серия 4, История. Регионоведение. Международные отношения. - 2017. - Т. 22, № 2. - С. 69-75.

Узкий перешеек между Волгой и Доном, издревле получивший название переволоки, в начале XIX в. приобрел всероссийское значение. Это направление стало едва ли не единственным для снабжения лесом и промышленными товарами бурно развивавшихся Приазовья и Северного Кавказа. Посад Дубовка, откуда начиналась дорога на Дон, превратился в один из крупнейших центров торговли на Юге России [7, с. 116-122]. По данным современной исследовательницы Э.Г. Истоминой, уже в 1811 г. грузооборот Дубовской пристани составил 7218600 рублей [6, с. 116-117]. Неудивительно, что в первой половине XIX в. появилось несколько проектов строительства железных дорог по этому направлению.

Первые предложения о желательности соединения Волги и Дона железной дорогой на паровой тяге появились еще до начала «железнодорожной эры» в России. Так, уже в апреле 1834 г. в Главное управление путей сообщения и публичных зданий (далее - ГУПС) поступило прошение коллежского советника А. Бестужева о пользе устройства железной дороги между Волгой и Доном. В записке были подробно представлены экономические выгоды, которые принесет обществу это предприятие. Сам же проситель, однако, не собирался строить данную дорогу. Записка имела вид совета правительству, как лучше и дешевле построить дорогу. По мнению Бестужева, железную дорогу ввиду ее огромной общественной значимости должно было строить государство. Нужные для постройки материалы могли быть легко доставлены по Волге с казенных чугунолитейных заводов Пермской губернии и с шепелевских заводов близ Мурома, для земляных работ можно было бы употребить казенных и удельных крестьян пензенской губернии, нуждающихся в заработке. Для начала работ, по подсчетам Бестужева, достаточно было выделить из казны 2 млн руб. ассигнациями. Понимая, что столь грандиозная стройка может оказаться для государства непосильным бременем, Бестужев предлагал привлечь к ней частные пожертвования. «Русское дворянство, купечество и заводчики, движимые патриотизмом, - писал он, - вероятно, пожертвуют значительные суммы на сие предприятие, чтобы не одно правительство несло издержки на оное». В качестве почина проситель обязался первым жертвовать ежегодно впредь до окончания работ свое годовое жалованье в 5500 руб. ассигнациями и собственных денег по 1000 руб. ассигнациями. Несмотря на патриотический порыв Бестужева, его предложение оказалось невостребованным. Аргументы просителя, касающиеся выгод, которые могла принести железная дорога, показались ведомству путей сообщения слишком приблизительными и неопределенными, а предложения - абстрактными. Это было верно - в своей записке он никак не коснулся, например, трассы будущей дороги. Бестужеву сообщили о необходимости представить точные расчеты и предложения, но никакого ответа от него не последовало. Бестужев не мог и не собирался проводить настоящие изыскания, его целью, как представляется, было лишь обратить внимание правительства на одно из полезных для народного хозяйства предприятий. Ведомство путей сообщения, напротив, отнеслось к нему, как к настоящему предпринимателю, затребовав формальное обоснование коммерческого проекта. Идея же соединения Волги и Дона железнодорожным полотном не нашла у специалистов поддержки. Предложение Бестужева было «оставлено без последствий» [1, с. 127-128].

Большой поток грузов, перевозившийся по Волго-Донской переволоке, продолжал привлекать внимание прожектеров. В архиве князей Всеволожских сохранилась анонимная записка с детальным обоснованием устройства железной дороги между Волгой и Доном. Записка не датирована, но в ее тексте содержатся данные о перевозках по этому направлению за 1835-1836 гг., следовательно, проект мог появиться не ранее 1837 года. Неизвестный автор рассмотрел три варианта железной дороги - от Царицына к Вертячим хуторам, от Царицына до Калачевского затона и от Дубовки до Качалинской станицы. Наиболее выгодным он счел третье направление, 
где уже давно проходил главный гужевой шлях. В проекте рассматривались два варианта железной дороги - на конной и паровой тяге. В первом случае затраты на сооружение дороги, по подсчетам автора, могли составить 1661615 рублей. Вариант с паровой тягой обошелся бы гораздо дороже - 2235765 рублей $[5$, л. 7,12$]$.

Как известно, первая железная дорога в России открылась в 1837 г. и соединила Петербург с Царским Селом. Она не имела народно-хозяйственного значения и являлась скорее экспериментом. Тем не менее этот опыт на практике показал скептикам, что железнодорожное сообщение в России осуществимо. Принято считать, что в царствование Николая I была построена лишь казенная Петербурго-Московская железная дорога, а ни одной частной дороги, несмотря на многочисленные ходатайства, так и не появилось. На самом деле одна такая дорога была разрешена и построена. 29 января 1843 г. в ГУПС обратились с ходатайством об учреждении акционерной компании для строительства и эксплуатации конно-железной дороги от посада Дубовки до станицы Качалинской на Дону обер-егермейстер Д.В. Васильчиков и коммерции советник Н.А. Попов. Вскоре к ним присоединился действительный статский советник А.И. Сабуров. После рассмотрения ходатайства 18 июня 1843 г. главноуправляющий путями сообщения вошел в Комитет министров с представлением, в котором высказался в поддержку проекта как полезного для «торговой промышленности края» и к тому же не требующего от правительства никаких привилегий. Это положение Комитета министров об учреждении компании для устройства железно-конной дороги между Волгой и Доном было утверждено Николаем I 3 июля 1843 г. [4, № 17007.]. Движение по этой дороге открылось летом 1846 г. [15, л. 4]. Однако эксплуатация дороги выявила целый ряд проблем. Частые поломки подвижного состава и ремонт плохо устроенного пути, конкуренция частных фурщиков, невозможность из-за рельефа местности довести дорогу до самых пристаней привели к тому, что дорога функционировала не в полную силу и не приносила большой прибыли. В 1854 г. дорога была официально признана закрытой [14, л. 60].
Идея железнодорожного строительства получила широкое признание в России только после позорного поражения в Крымской войне, не в последнюю очередь связанного с отсутствием в стране современных средств сообщения. В правительство хлынул целый поток предложений от частных лиц о строительстве тех или иных линий. Волго-Донское направление стало одним из самых популярных. Так, в феврале 1856 г. тайный советник барон А. Мейендорф предложил учредить компанию для устройства целой сети железных дорог - от Москвы к Черному морю, от Москвы до Саратова, от Курска к Балтийскому морю, от Москвы к Донецкому каменноугольному бассейну и, наконец, между Волгой и Доном. План этот был столь грандиозен, что чиновники ГУПС просто не поверили в способности барона организовать такое предприятие. Его прошение сочли несерьезным и отклонили [2, с. 296].

В мае 1856 г. ротмистр Кассель, инженер Жоффрио и инженер-механик Дависон просили разрешения составить акционерную компанию для устройства двух металлургических заводов - у Царицына и у станицы Мелиховской на Нижнем Дону общей производительностью 3 млн пудов чугуна и 2 млн пудов железа. Для удобства снабжения этих заводов сырьем и топливом, а также для вывоза готовой продукции будущие заводчики просили также разрешения на сооружение железных дорог между Волгой и Доном и от грушевских каменноугольных копей к Дону, а также на учреждение пароходства по Оке, Волге, Дону, Каспийскому, Черному и Азовскому морям. Для своей компании учредители запросили большие привилегии. Им должна была быть уступлена на вечные времена земля между Волгой и Доном шириной в 5 верст, от Саратова вверх по Волге на 5 верст и 1300 кв. верст в районе грушевских шахт. Компания получала право производить беспошлинно в течение 50 лет разработку каменного угля и железных руд по берегу Волги и Дона на расстоянии 100 верст от берега этих рек. Ее заводы освобождались на 50 лет от пошлин на руду и уголь, закупаемые у других лиц. На протяжении 50 же лет другим компаниям не разрешалось устраивать подобные заводы не только в Саратовской губернии и области вой- 
ска Донского, но и в Самарской и в Астраханской губерниях. Для осуществления этого плана предусматривался выпуск акций на 14 млн руб., однако капитал общества составлял только 12 млн рублей. По миллиону рублей должны были получить учредители компании и составители проекта (возможно, они же). Проект походил на самое очевидное надувательство, и чиновники ГУПС это прекрасно поняли. Просителям было отказано по нескольким основаниям. Во-первых, говорилось в ответе, железных руд в количестве, необходимом для заводов такой производительности, на Дону и Волге не имеется. Во-вторых, учредители вовсе не вкладывали своего капитала в компанию, что было подозрительно, и, в-третьих, требовали себе непомерных привилегий, допустить которые государство не могло [3, с. 93].

В ноябре 1858 г. неаполитанский консул в Таганроге де Росси подал прошение об учреждении железной дороги от Царицына до Таганрога. Главным обоснованием этого направления автор назвал мелководность Дона. Обилие перекатов на всем пути, начиная от междуречья Волги и Дона, изменчивый фарватер действительно создавали для донского судоходства большие проблемы. Существенно удорожала перевозку и необходимость перегружать товары в Ростове на мелкосидящие барки, чтобы миновать узкие и мелкие донские гирла в устье реки и доставить их в морской порт Таганрог. К тому же в зимнее время навигация на Дону прекращалась. Проведение железной дороги от Царицына напрямую к Таганрогу, по мнению де Росси, позволяло избавиться от этих препятствий. Однако эти доводы не встретили понимания в ГУПС. Чиновники все еще сомневались в преимуществе железных дорог перед пароходством. Кроме того, по их мнению, мелкосидящие донские пароходы могли доставлять грузы прямо в Керченский порт, без перегрузки в Таганрогском порту, недоступном в силу своей мелкости для крупных морских судов. На этом основании прошение де Росси было признано не заслуживающим внимания [3, с. 139].

В дискуссию о необходимости строительства железной дороги втянулась и провинция. В конце 1856 - 1857 г. на страницах «Саратовских губернских ведомостей» с рядом статей выступил редактор неофициальной части газеты, чиновник губернского статистического комитета Д.Л. Мордовцев, впоследствии ставший известным историком и писателем. Поводом для его выступлений как раз и стали слухи о предполагаемом строительстве железных дорог на Юге России. Представив подробные цифры торгового оборота Саратова, Мордовцев полностью поддержал идею строительства железной дороги Москва - Саратов как линии, связывающей все Нижнее Поволжье с центром страны. По его подсчетам, эта железная дорога могла вывозить с Волги до 10 млн пудов хлеба, 7 млн пудов соли, 1,5 млн пудов рыбы, 1,5 млн пудов сала и множество других сельскохозяйственных товаров. В то же время идею строительства Волго-Донской дороги Мордовцев посчитал недостаточной. Перечислив неудобства этого направления (двойная перегрузка, мелководье Дона и его гирл), он подошел к проблеме с более широкой точки зрения: «Необходимо более прочное соединение главной жилы России (Волга, по счастливому выражению барона Гакстгаузена) с южными морями, открывающими нам свободный путь в Европу; для поддержки такой важной страны, как Кавказ и Закавказье, необходима здесь железная дорога; необходима она для колонизации прекрасных и плодоносных задонских степей, могущих сделаться впоследствии такой же житницей для Азии, как наши понтийские страны - для Европы; она необходима, наконец, как путь, имеющий быть спасительным для России в военное время» [10]. По мнению Мордовцева, железная дорога должна была напрямую связать Волгу с морем, хотя бы и Азовским, чтобы избавиться от непостоянства донского судоходства. В то же время он выступил против выдвинутого Э. фон Траутфеттером направления Дубовка - Феодосия. Мордовцев писал, что по этому пути железная дорога будет вынуждена пересекать местность, изобилующую возвышенностями и оврагами, а также две полноводные реки Дон и Северский Донец. Это потребует больших искусственных сооружений и приведет к огромным затратам. Саратовский публицист выступил за другое направление - от Сарепты на Ейск. Здесь была удобная гавань для устройства порта на Волге - устье реки Сар- 
пы, здесь Ергенинская возвышенность уходила от Волги и на всем протяжении до самого Ейска степь была практически плоская, реки маловодны и летом почти пересыхали. Вдобавок здесь трасса прошла бы по малоплодородной местности и плата владельцам земли за ее отчуждение была бы минимальной. Наконец, убеждал Мордовцев, это направление было значительно короче дубовско-феодосийского [11].

Между тем на пороге ГУПС появились просители, личности которых и предложения впервые заинтересовали путейское ведомство. 12 мая 1856 г. туда поступило прошение коллежского секретаря А.А. Деревицкого и графа Н.И. Мусина-Пушкина. Обосновывая его растущими потребностями торговли и быстрым увеличением добычи донецкого угля, они испрашивали разрешения на постройку железной дороги между Волгой и Доном. Создаваемому для этих целей акционерному обществу должны были быть предоставлены следующие привилегии. В пользование компании предоставлялась полоса земли вдоль линии дороги шириной в 100 саженей с платой по 4 руб. 50 копеек. Для насаждения деревьев, другим лицам на протяжении 50 лет запрещалось строить железные дороги в том же направлении. Правительство гарантировало доход на капитал в размере $4 \%$, по истечении 50 лет эксплуатации общество передавало дорогу в казну. Для снабжения топливом компания просила обязать создаваемое в это же время Грушевское каменноугольное общество продавать ей антрацит не дороже 4 коп. за пуд, а если это окажется невозможным, предоставить место для собственных разработок угля. Наконец, компания должна была иметь собственные пристани на обеих реках [14, л. 48-51].

Главное управление путей сообщения благосклонно отнеслось к этому ходатайству. Возможно, помогло согласие просителей полностью оплатить предварительные изыскания за свой счет. 21 июня 1856 г. Александр II дал согласие на проведение изысканий. Всего на их производство и составление проекта железной дороги Деревицкий и Мусин-Пушкин выделили 8 тыс. рублей. Общее руководство изысканиями было поручено выдающемуся инженеру, одному из главных строителей Петербурго-Московской железной дороги
П.П. Мельникову. Работы прошли быстро и уже в феврале 1857 г. проект и смета были окончены $[14$, л. 78]. Общая сметная стоимость строительства дороги по расчетам инженеров-путейцев составила 5714260 руб. в случае строительства двухпутного полотна и туннеля под водоразделом или 3318730 руб. в случае выбора варианта с наклонной плоскостью [8, с. 164-171].

27 марта 1857 г. готовый проект и смета были направлены заказчикам. Видимо, они рассчитывали на меньшие затраты. Уже через две недели после ознакомления с проектом и сметой Деревицкий предпочел выйти из дела и передать все свои права в учреждаемой компании коллежскому советнику Н.А. Новосельскому [14, л. 80]. Но, судя по всему, и второй компаньон Деревицкого также разочаровался в осуществимости задуманного предприятия. От него так и не последовало никаких попыток реально организовать акционерную компанию. Зато идея соединения Волги с Доном серьезно заинтересовала других предпринимателей. В декабpe 1857 г. в ГУПС поступило новое прошение об учреждении компании по устройству Волго-Донской железной дороги, а также судоходства по Дону. Учредителями вызвались быть коллежский советник Н.А. Новосельский, коммерции советник В.А. Кокорев и генерал-майор П.П. Мельников, только что руководивший изыскательскими работами [3, c. 130]. У частие в компании П.П. Мельникова фактически открыло новую для России ситуацию участия чиновников в акционерных компаниях [9, с. 108-112]. В.А. Кокорев (известный делец, сколотивший на винных откупах миллионное состояние) в это время активно вкладывал деньги в различные проекты, связанные с транспортом и восточной торговлей. Н.А. Новосельский был одним из основателей пароходного общества на Каспийском море «Кавказ». В августе 1856 г. Кокорев и Новосельский вошли в число учредителей черноморского Российского общества пароходства и торговли. Через год, в августе 1857 г., они же учредили Закаспийское торговое товарищество.

Н.А. Новосельский уже являлся преемником Деревицкого в проекте компании с Мусиным-Пушкиным, и учредителям нового об- 
щества оставалось только освободиться от последнего, чтобы получить возможность воспользоваться уже готовым проектом железной дороги. Скорее всего, Мусину-Пушкину просто заплатили за отказ от прав на проект. По крайней мере в финансовом отчете нового общества содержится упоминание о приобретении первоначального проекта дороги за 23260 рублей [13]. 19 июля 1858 г. Александр II утвердил устав Общества Волго-Донской железной дороги и пароходства по Дону и Азовскому морю. Именно этой дороге суждено было стать первой на всем Юге России. После недолгого строительства регулярное движение по ней открылось 27 апреля 1862 года [12].

\section{СПИСОК ЛИТЕРАТУРЫ}

1. Боричевский, И. П. Предположения частных лиц об устройстве железных дорог, поступившие в Главное управление путей сообщения и публичных зданий до 1860 г. / И.П.Боричевский // Журнал Главного управления путей сообщения и публичных зданий. - 1863. - Т. 39, кн. 1. - С. 128-162.

2. Боричевский, И. П. Предположения частных лиц об устройстве железных дорог, поступившие в Главное управление путей сообщения и публичных зданий до 1860 г. / И. П. Боричевский // Журнал Главного управления путей сообщения и публичных зданий. - 1863. - Т. 39, кн. 2. - С. 262-318.

3. Боричевский, И. П. Предположения частных лиц об устройстве железных дорог, поступившие в Главное управление путей сообщения и публичных зданий до 1860 г. / И. П. Боричевский // Журнал Главного управления путей сообщения и публичных зданий. - 1863. - Т. 40, кн. 1. - С. 91-139.

4. Высочайше утвержденное положение Комитета министров, объявленное Главноуправляющим путями сообщения и публичными зданиями: об учреждении компании для устройства железноконной дороги между Волгой и Доном // Полное собрание законов Российской Империи. Собрание второе. - СПб. : Отд. 1, 1843. - Т. 18. - 842 с.

5. Записка неустановленного лица об устройстве в 1837 г. железной дороги между Волгой и Доном, с приложением сметы // Российский государственный исторический архив (далее - РГИА). Ф. 652.- Оп. 1. - Д. 1100.

6. Истомина, Э. Г. Водные пути России во второй половине XVIII - начале XIX в. / Э. Г. Истомина. - М. : Наука, 1982. - 277 с.

7. Кузнецов, В. В. Посад Дубовка в экономике Поволжья (XVIII-XIX вв.) / В. В. Кузнецов // Вопросы истории. - 2006. - № 12. - С. 116-122.
8. Луночкин, А. В. К истории проектирования Волго-Донской железной дороги (1856-1859 гг.) / А. В. Луночкин // Историческое и этнокультурное развитие Нижнего Поволжья : сб. науч. ст. по материалам конф. - Волгоград : Литера, 2003. C. 164-171.

9. Луночкин, А. В. Служба и выгода: государственные служащие в руководстве акционерного общества Волго-Донской железной дороги (18581878 гг.) / А. В. Луночкин // Власть. - 2009. - № 5. C. 108-112.

10. Мордовцев, Д. Л. Несколько новых данных относительно сообщения между Сарептою и Ейском // Саратовские губернские ведомости. - 1857. 2 февр. (№ 5).

11. Мордовцев, Д. Л. О сарепто-ейской железной дороге / Д. Л. Мордовцев // Саратовские губернские ведомости. - 1857. - 17 авг. (№ 33).

12. Отчет акционерного общества ВолгоДонской железной дороги и пароходства // Саратовские губернские ведомости. - 1862. - 9 июня (№ 23).

13. Отчет правления акционерного общества Волго-Донской железной дороги и пароходства по Дону и Азовскому морю // Журнал для акционеров. - 1860. - Прибавление к № 173.

14. По проекту устройства железной дороги между Волгою и Доном // РГИА. - Ф. 219. - Оп. 1. Ч. 4. - Д. 5488.

15. По просьбе учредителей конно-железной дороги между Волгою и Доном о принятии этой дороги в казну // РГИА. - Ф. 1271. - ОП. 1. - Д. 9.

\section{REFERENCES}

1. Borichevskiy I.P. Predpolozheniya chastnykh lits ob ustroystve zheleznykh dorog, postupivshie v Glavnoe upravlenie putey soobshcheniya i publichnykh zdaniy do $1860 \mathrm{~g}$. [Assumptions of Individuals about the Construction of the Railways Submitted to the General Directorate of Railways and Public Buildings before 1860]. Zhurnal Glavnogo upravleniya putey soobshcheniya i publichnykh zdaniy, 1863, vol. 39, book 1, pp. 128-162.

2. Borichevskiy I.P. Predpolozheniya chastnykh lits ob ustroystve zheleznykh dorog, postupivshie v Glavnoe upravlenie putey soobshcheniya i publichnykh zdaniy do $1860 \mathrm{~g}$. [Assumptions of Individuals about the Construction of the Railways Submitted to the General Directorate of Railways and Public Buildings before 1860]. Zhurnal Glavnogo upravleniya putey soobshcheniya i publichnykh zdaniy, 1863, vol. 39, book 2, pp. 262-318.

3. Borichevskiy I.P. Predpolozheniya chastnykh lits ob ustroystve zheleznykh dorog, postupivshie $\mathrm{v}$ 
Glavnoe upravlenie putey soobshcheniya i publichnykh zdaniy do $1860 \mathrm{~g}$. [Assumptions of Individuals about the Construction of the Railways Submitted to the General Directorate of Railways and Public Buildings before 1860]. Zhurnal Glavnogo upravleniya putey soobshcheniya $i$ publichnykh zdaniy, 1863, vol. 40, book 1, pp. 91-139.

4. Vysochayshe utverzhdennoe polozhenie Komiteta ministrov, obyavlennoe Glavnoupravlyayushchim putyami soobshcheniya i publichnymi zdaniyami: Obuchrezhdenii kompanii dlya ustroystva zhelezno-konnoy dorogi mezhdu Volgoy i Donom [The Highly Approved Provision of the Committee of Ministers, Announced by the Main Direction of Communications and Public Buildings: On the Establishment of a Company for the Installation of a RailwayHorse Road between the Volga and the Don Rivers]. Polnoe sobranie zakonov Rossiyskoy Imperii. Sobranie vtoroe [Complete Collection of Laws of the Russian Empire. $2^{\text {nd }}$ Collection]. Saint Petersburg, 1843, vol. 18. 842 p.

5. Zapiska neustanovlennogo litsa ob ustroystve v 1837 g. zheleznoy dorogi mezhdu Volgoy i Donom, s prilozheniem smety [Note by Unidentified Person in 1837 about Construction of the Railroad between the Volga and the Don Rivers, with the Application of Estimates]. Rossiyskiy gosudarstvennyy istoricheskiy arkhiv [The Russian State Historical Archive], F. 652, Op. 1, D. 1100.

6. Istomina E.G. Vodnye puti Rossii vo vtoroy polovine XVIII - nachale XIXvv. [Waterways of Russia in Second Half of the $18^{\text {th }}$ - early $19^{\text {th }}$ Centuries]. Moscow, Nauka Publ., 1982.277 p.

7. Kuznetsov V.V. Posad Dubovka v ekonomike Povolzhya (XVIII-XIX vv.) [Dubovka Suburb in the Economy of the Volga Region ( $18^{\text {th }}-19^{\text {th }}$ Centuries)]. Voprosy istorii, 2006, no. 12, pp.116-122.

8. Lunochkin A.V. K istorii proektirovaniya VolgoDonskoy zheleznoy dorogi (1856-1859 gg.) [On the History of Designing the Volga-Don Railway (1856-1859)]. Istoricheskoe i etnokulturnoe razvitie Nizhnego Povolzhya: sbornik nauchnykh statey po materialam konferentsii [Historical and Ethno-Cultural Development of the Lower Volga Region: Collection of Conference Proceedings]. Volgograd, Litera Publ., 2003, pp.164-171.

9. Lunochkin A.V. Sluzhba i vygoda: gosudarstvennye sluzhashchie $v$ rukovodstve aktsionernogo obshchestva Volgo-Donskoy zheleznoy dorogi (1858-1878 gg.) [Service and Benefit: Officials in the Direction of the Volga-Don Railway Joint-Stock Company (1858-1878)]. Vlast, 2009, no. 5, pp. 108-112.

10. Mordovtsev D.L. Neskolko novykh dannykh otnositelno soobshcheniya mezhdu Sareptoyu i Eyskom [Some New Data on the Communication between Sarepta and Ejsk]. Saratovskie gubernskie vedomosti, 1857, no. 5 (Feb. 2).

11. Mordovtsev D.L. O sarepto-eyskoy zheleznoy doroge [About the Sarepta-Yeisk Railway]. Saratovskie gubernskie vedomosti, 1857, no. 33 (Aug. 17).

12. Otchet aktsionernogo obshchestva VolgoDonskoy zheleznoy dorogi i parokhodstva [Report of the Volga-Don Railroad and Shipping Joint Stock Company]. Saratovskie gubernskie vedomosti, 1862, no. 23 (June 9).

13. Otchet pravleniya aktsionernogo obshchestva Volgo-Donskoy zheleznoy dorogi i parokhodstva po Donu i Azovskomu moryu [Report of the Board of the Volga-Don Railroad and Shipping Joint-Stock Company on the Don River and the Sea of Azov]. Zhurnal dlya aktsionerov, 1860, Addition to no. 173 .

14. Po proektu ustroystva zheleznoy dorogi mezhdu Volgoyu i Donom [According to the Project of the Construction the Railway between the Volga and the Don Rivers]. Rossiyskiy gosudarstvennyy istoricheskiy arkhiv [The Russian State Historical Archive], F. 219, Op. 1, Part 4, D. 5488.

15. Po prosbe uchrediteley konno-zheleznoy dorogi mezhdu Volgoyu i Donom o prinyatii etoy dorogi v kaznu [Upon the Request of the Founders of Railway-Horse Road between the Volga and the Don Rivers about Its Transfer to State Property]. Rossiyskiy gosudarstvennyy istoricheskiy arkhiv [The Russian State Historical Archive], F. 1271, Op. 1, D. 9.

\section{Information about the Author}

Andrey V. Lunochkin, Candidate of Sciences (History), Associate Professor, Department of History of Russia, Volgograd State University, Prosp. Universitetsky, 100, 400062 Volgograd, Russian Federation, kvolguhist@inbox.ru, histrus@volsu.ru, http://orcid.org/0000-0002-7431-8906.

\section{Информация об авторе}

Андрей Валентинович Луночкин, кандидат исторических наук, доцент кафедры истории России, Волгоградский государственный университет, просп. Университетский, 100, 400062 г. Волгоград, Российская Федерация, kvolguhist@inbox.ru, histrus@volsu.ru, http://orcid.org/0000-00027431-8906. 